\title{
SciDoc
}

Infer, Interpret \& Inspire Science

International Journal of Dentistry and Oral Science (IJDOS)

ISSN: 2377-8075

\section{Recent Advances in Role of Matrix metalloproteinases in Some Dental Diseases}

Review Article

Javed $\mathrm{MH}^{1 *}$, Sabahat Hameed ${ }^{2}$

${ }^{1}$ Professor of Basic Medical Sciences, College of Medicine King Saud bin Abdulaziz University For Health Sciences, HS National Guards Health Affairs King Abdulaziz, Medical City Jeddah, Saudi Arabia.

${ }^{2}$ Department of Endodontics, Nishter Institute of Dentistry, Multan, Pakistan.

\section{Abstract}

The common types of dental diseases are caries, periapical, pulpitis, gingivitis, oral infectious diseases and hereditary lesions. These chronic diseases are supposed to be due to interaction between the bacteria in oral cavity and the host. The progression of these diseases needs some major changes in the biochemistry and physiology of connective tissues where different types of collagens are present. In dental diseases the specific collagen is degenerated/lost in connective tissue probably due to matrix metalloproteinases (MMPs), reactive oxygen species (ROS), apoptosis and antioxidants. In this short review we discussed only the role MMPs in dental carries and periodontitis.

Keywords: Dental Caries, Periodontitis, MMP.

\section{Introduction}

Dental health is not only essential but also an integral part of systemic health throughout the human life. Dental diseases are varied and may be of soft tissue origin (gingivitis) or may be of hard tissue (caries or periodontitis). Dental diseases may be simple like caries (cavitation) or complex one such as tumors and cyst of dental origin and may also cause more dangerous and life threatening problems $[24,41]$. Dentition (teeth) plays an important role in mastication (chewing), speech (pronunciation of certain consonants and facial expression), cheek fullness(avoiding aged appearance) and also maintains facial height. The dental diseases may affect any of the above said functions of teeth [26]. The common types of human's dental diseases are caries, periapical and pulpal inflammation (pulpitis), gingival (gingivitis), periodontal (gumperiodontics) problems, oral infectious diseases, trauma from injuries, and hereditary lesions [41]. The inflammatory process is often associated with free radicaldamage and oxidative stress [39], $[24,29]$. These diseases are considered as chronic problems and are supposed to be due to interaction between the bacteria in oral cavity (oral flora) and the host. The progression of these diseases needs some major changes in the biochemistry and physiology of connective tissues because these tissues hold cells together to make tissues and organs in the body [42]. One of the important proteins in the connective tissue is the collagen, which is of different types and depends upon the tissues where it is present [19]. It is observed and suggested that in dental diseases the specific collagen is degenerated or lost in connective tissue probably due to matrix metalloproteinases (MMPs), reactive oxygen species (ROS), apoptosis and antioxidants. In this short review we discussed only the role MMPs in dental carries and periodontitis.

\section{Matrix Metalloproteinases (MMPs)}

These endopeptidases enzymes belong to the M10A subfamily of metallopeptidases, which contain zinc methioninein their active site $[1,28]$. They cut the extracellular matrix (ECM)/core matrisome proteins into various small peptides by hydrolyzing inner peptide bonds. Their activity depends upon $\mathrm{Ca}++$ ions. MMPs are different from other endopeptidases because they do not function in the absence of metal ions [37]. These enzymes not only degrade collagens and ECM proteins but can also regulate

\section{*Corresponding Author:}

Masood-ul-Hassan Javed, BSc, PhD,

Professor of Basic Medical Sciences College of Medicine King Saud bin Abdulaziz University-HS National Guards Health Affairs King Abdulaziz Medical City Jeddah-21423, Saudi Arabia.

Tel: 00966592739044

Fax: 0096622245769

E-mail: masoodjaved@hotmail.com

\section{Received: September 05, 2016}

Accepted: October 13, 2016

Published: October 19, 2016

Citation: Javed MH, Sabahat Hameed (2016) Recent Advances in Role of Matrix Metalloproteinases in Some Dental Diseases. Int J Dentistry Oral Sci. 3(10), 344-347. doi: http://dx.doi.org/10.19070/2377-8075-1600070

Copyright: Javed $\mathbf{M U}^{\circ}$ 2016. This is an open-access article distributed under the terms of the Creative Commons Attribution License, which permits unrestricted use, distribution and reproduction in any medium, provided the original author and source are credited. 
the activity of many bioactive molecules, like cell surface receptors, the release of apoptotic ligands (FAS ligand) and cytokine/ chemokine inactivation $[16,35]$. Thus MMPs are also called as hydrolyse components of the ECM because they have the tendency/activity to break matrix components. These MPPs modulate the activity of the above-mentioned factors either by direct cleavage, or release them from ECM bound stocks, like buffers [5]. These enzymes are also supposed to play a major role in cell behaviors during critical events (physiological or pathological) of life such as cell migration, proliferation (dispersion/adhesion), differentiation, development, embryogenesis, angiogenesis, apoptosis, cell defense, as well as wound healing [1]. In this way they coordinate remodelling of extracellular matrix by accurate synthesis and depletion of proteins like collagens and others in ECM which is promoted and controlled by various proteases [28]. These include aspartic protease, cysteine protease, MPPs and serine protease [19]. Up till now the researchers have identified 24 MMP genes in humans and 26 members have been listed for these MPPs [23]. These MMP enzymes have been classified in to 6 major groups namely collagenases, gelatinases, matrilysins, membrane type MMPs, other MPPs and stromelysins [9]. All six MMPs contain furin cleavage site in the pro-peptide.

In predentine (odontoblasts) and dentin, another class of MMPs are present called as collagenase MMP-1, the gelatinases MMP-2 and MMP-9, MMP-3 (stromelysin-1), the MMP-2 activator MT1MMP, and enamelysin (MMP-20) [9].

The collagenases are of different types depending upon their site of action and product formation. They degrade triple-helical fibrillar structure of collagens into various specific fragments and are the major components dentin (and cartilage and bone as well).

The different types of gelatinases mainly act on type-IV collagen and gelatin. The stromelysins act on proteins but unable to cleave the triple-helical fibrillar collagens [23].

It is known that all these MMPs are synthesized and secreted by the tissue cells as inactive form known as Zymogen (proenzymes) and then are activated by complex extracellular modulators [13]. As mentioned by Pardo, et al., (2016)[28], these MMPs are activated mostly in ECM or at the cell surface by molecules like $\alpha 2$-macroglobulin and the membrane-associated reversioninducing Cys-rich protein with Kazal motifs (RECK). However, some of them can also be activated in side the intracellular organelles, including nuclear localization where they act on intracellular substrates, or may function as transcription factors [22]. These enzymes in turn are controlled by endogenous tissue inhibitors of (called as TIMPS) that inhibit the activity of MMPs and keep them at physiological desired levels (by the processes of homeostasis). At present the family of TIMPS consists of TIMP1, TIMP-2, TIMP-3 and TIMP-4 [23, 38]. This remodelling of ECM is quite complex because these MPPs and their modulators are strongly regulated at multiple levels. Some are controlled at gene expression (transcriptional regulation), other by growth factors, cytokines, hormones, and cell-ECM, and some by cell-cell interactions. The stability of their mRNA, efficiency of protein translational and role played by microRNAs are thought to involve as post-transcriptional regulatory processes [13, 28]. Imbalance in the homeostasis of MMP and TIMP is responsible for the development of pathological conditions [1, 6, 28, 33]. Thus it is the dis-regulation of the balance between MMPs and TIMPs that leads to many chronic systemic as well as dental diseases. It is observed that some nonspecific endogenous inhibitors can regulate the activity of MMP [9]. Similarly the search of exogenous modulators for these MMPs or TIMP can be used as drugs to treat various diseases of ECM including dental in origin. Most of the synthetic inhibitors have a chelating group that binds very strongly (like irreversible inhibitor) with the zinc atom at the active site of the MMP. The most common compounds in this category are hydroxamates, thiol, carboxylates and phosphinyls. Hydroxymates are particularly potent inhibitors of MMPs and other zincdependent enzymes, due to their bidentate chelation of the zinc atom. Other substitutents of these inhibitors are usually designed to interact with various binding pockets on the MMP of interest, making the inhibitor more or less specific for given MMPs. Clinical trials for many of these agents showed poor pharmacokinetic and lack of specificity as anticancer or for cardiovascular diseases. Thus they showed many undesired side effects $[2,7,27,40]$. The implication of MMPs and TIMPs in the dental disorders is vast and promising but due to complicated types very little is known the physiology of each of the MMPs. Therefore the understanding of the physiology \& Biochemistry of these enzymes from the molecular, to the cellular and tissue levels, where these molecular complexes operate, will be necessary for the development of newtherapeutic agents [14].

\section{Dental Caries}

It is one of the most common infectious diseases worldwide [29]. As quoted by the WHO (2012), "worldwide, 60-90\% of school children and nearly $100 \%$ of adults have dental cavities, often leading to pain and discomfort". It is an irreversible disease caused mostly by Streptococcus mutans, Streptococcus sobrinus and Lactobacillus species of the oral cavity (oral flora). These bacteria form a complex community, which adheres on surfaces of tooth in a gelatinous mat, orbiofilm, or dental plaque. These bacteria produce lactic acid (mostly) by degrading sugar component of diet. This acid then diffuses through dental calcified tissues and thus the $\mathrm{pH}$ at this point drops below 5.5. The acidic $\mathrm{pH}$ and probably heat activate "host" pro MMPs further from both dentin and saliva. This activation is supposed to be due to the conformational change of the propeptide and thus induce the cysteine switch, which is necessary for the activation process $[9,10]$. It is suggested that although the MMPs are activated by the acidic $\mathrm{pH}$ but they cannot degrade components of organic matrix at this $\mathrm{pH}$. As the $\mathrm{pH}$ drops the salivary buffer system neutralizes the acid and may increase in the $\mathrm{pH}$ towards 7.4 at the spot of demineralised dentin. This $\mathrm{pH}$ environment allows activated MMPs to degrade the organic matrix $[9,34]$. The activated enzymes then dissolute mineral crystals in that local area and causes cavitation [8, 23]. It is known that dentin contains more organic material and water than enamel so this part of tooth acts, thus more preferable substrate for enzymatic degradation (due to host or bacterial proteinases). The organic components of dentine consist of type-I collagen $(90 \%)$ and phosphorylated proteins called dentinphosphosialoprotein (DSPP) (10\%). DSPP forms dentin sialoprotein (DSP) \& dentin phosphoprotein (DPP) immediately after its secretion [23].

It is also observed that many Growth Factors (GFs) like Transforming GF-beta, fibroblast growth factor-2 (FGF-2) \& Insulin like growth factor 1 and 2 (ILGF-1 \&-2) are also present in dentin. According to researchers as dental caries starts and ECM 
degradation takes place, these GFs are then released and stimulate odontoblasts to form compensatory dentin materials [9, 12]. It is proposed that bacterial collagenases are the main "culprit" for the catabolism of organic matrix. However, now it has been found that MMPs derived from host have more important role to degrade organic matrix of dentin. These enzymes have been to be present both in dentin and saliva. It has been proposed that gingival crevecular fluid (GCF) is the main source of salivary MMPs $[3,9,31]$.

\section{Biochemical Basis of Periodontitis}

Periodontitis is an inflammatory condition of gingival tissue, due to which there is a loss of periodontal ligament that is attached with bones for functional support. To initiate and development of this disease, a plaque is observed at the affected areas. At the same time it is also believed that the physiological response of host to the pathogen is mainly responsible bone loss and breakdown of the respective connective. It is proposed that the MMPs, prostanoids (PGs) and cytokines originated from host are responsible for activation of the osteoclastic activity, which then destroys the periodontium tissue [36]. Due to exogenous and endogenous causative factors collagen degradation then starts in persons susceptible to this disease. Inflammatory process then extends laterally and apically and towards deeper connective tissues and bone as well [23]. Due to this inflammatory process, at the place of lesion, phagocytes and other defence cells are recruited (known as inflammatory cells). The macrophages secrete interleukins (ILs), PG-E2, MMPs and tumor necrosis factor alpha (TNF $\alpha$ ) $[25,36]$. For this disease, initial hypothesis was that collagenases that initiate the process of this disease are secreted from infected or normal oral flora. However now it is believed that the host collagenases, especially MMP-1 (MMP-1) cut collagens of the connective tissue at a single point and thus only two fragments are produced [11]. These are the best substrates for microbial proteolytic enzymes that produce different types of short peptides because they hydrolyse these fragmented collagens at multiple sites $[32,36]$. In an experimental study, Makela et al., (1994) [20] have demonstrated that compared to normal tissues there were higher level of MMP-2 \& MMP-9 gelatinases in periodontitis tissues. At the same time as the inflammatory process moves towards the apical side then the levels of ILs, PGs, and TNF $\alpha$ become more compared to normal tissues. This altered micro-environmental activates the osteoclasts that initiate the resorption of alveolar bone. It is also believed that MMP-2 plays vital role in bone remodelling while MMP-14 (present at border of osteoclasts) helps for the interaction between matrix and osteoclasts $[17,18]$. The collagen remnants left over by osteoclasts in the lacunae of affected bones are cleared by MMp-13 already present in resorption lacunae [30].

\section{References}

[1]. Ayuk SM, Abrahamse H, Houreld NN (2016) The Role of Matrix Metalloproteinases in Diabetic Wound Healing in relation to Photobiomodulation. J Diab Res. 2016: 2897656.

[2]. Becker DP, Barta TE, Bedell LJ, Boehm TL, Bond BR, et al., (2010) Orally active MMP-1 sparing $\alpha$-tetrahydropyranyl and $\alpha$-piperidinylsulfone matrix metalloproteinase (MMP) inhibitors with efficacy in cancer, arthritis, and cardiovascular disease. J Med Chem. 53(18): 6653-6680.

[3]. Birkedal-Hansen H (1993) Role of matrix metalloproteinase's in human periodontal diseases. J Periodontol. 64(5): 474-484.

[4]. Birkedal-Hansen H, Moore WG, Bodden MK, Windsor LJ, Birkedal-Hansen B, et al., (1993) Matrix metalloproteinase's review. Cri. Rev Oral Biol
Med. 4(2): 197-250.

[5]. Bonnans C, Chou J, Werb Z (2014) Remodelling the extracellular matrix in development and disease. Nat Rev Mol Cell Biol.15(12): 786-801.

[6]. Brew K, Nagase H (2010) The tissue inhibitors of metalloproteinases (TIMPs): An ancient family with structural and functional diversity. Biochim Biophys Acta. 1803(1): 55-71.

[7]. Brown PD (1997) Matrix metalloproteinases inhibitors in the treatment of cancer. Med. Oncol. 14(1): 1-10.

[8]. Caufield PW, Griffen AL (2000) Dental caries. An infectious and transmissible disease. Pediatr Clin North Am. 47(5): 1001-1019.

[9]. Chaussain-Miller C, Fioretti F, Goldberg M, Menashi S (2006) The Role of Matrix Metalloproteinase's (MMPs) in Human Caries. J Dent Res. 85(1): 22-32.

[10]. Dayan D, Binderman I, Mechanic GL (1983) A preliminary study of activation of collagenase in carious human dentine matrix. Arch Oral Biol. 28(2): 185-187.

[11]. Dennison DK, Dyke TE (1997) The acute inflammatory response and the role of phagocytic cells in periodontal health and disease. Periodontology. 14: 54-78.

[12]. Farges JC, Romeas A, Melin M, Pin JJ, Lebecque S, et al., (2003) TGFbeta1 induces accumulation of dendritic cells in the odontoblast layer. J Dent Res. 82(8): 652-656.

[13]. Gaffney J, Solomonov I, Zehorai E, Sagi I (2015) Multilevel regulation of matrix metalloproteinases in tissue homeostasis indicates their molecular specificity in vivo. Matrix Biol. (44-46): 191-199.

[14]. Garcia-Pardo A, Opdenakker G (2015) Nonproteolytic functions of matrix metalloproteinases in pathology and insights for the development of novel therapeutic inhibitors. Metalloproteinases in Medicine. 2: 19-28.

[15]. Goldberg M, Septier D, Bourd K, Hall R, George A, et al., (2003) Immunohistochemical localization of MMP-2, MMP-9, TIMP 1, and TIMP-2 in the forming rat incisor. Connect Tissue Res. 44: 143-153.

[16]. Itoh Y (2015) Membrane-type matrix metalloproteinases: Their functions and regulations. Matrix Biol. (44-46): 207-223.

[17]. Katakwar F, Metgud R, Naik S, Mittal R (2016) Oxidative stress marker in oral cancer: A review. J Can Res Therap. 12(2): 438-446.

[18]. Kerkela E, Saarialho-Kere U (2003) Matrix metalloproteinase's in tumor progression: focus on basal and squamous cell skin cancer. Exp. Dermatol. 12(2): 109-125.

[19]. Lodish H, Berk A, Zipursky SL, et al., (2000) Collagen: The Fibrous Proteins of the Matrix. In Molecular Cell Biology, (4th Edn), New York: W. H. Freeman.

[20]. Makela M, Salo T, Uitto VJ, Larjava H (1994) Matrixmetalloproteinases (MMP 2 \& 9) of oral cavity: cellular origin and relationship to periodontal status. J Dent Res. 73(8): 1397-1406.

[21]. Mandel ID, Gaffar A (1986) Calculus revisited. J Clin Periodontol. 13(4): 249-257.

[22]. Marchant DJ, Bellac CL, Moraes TJ, Wadsworth SJ, Dufour A, et al., (2014) A new transcriptional role for matrix metalloproteinase-12 in antiviral immunity. Nat Med. 20(5): 493-502.

[23]. Masthan KMK, Babu NA, Bhattacharjee T, Elumali M (2013) Biochemical markers- A tool to detect oral diseases. Int J Pharm Bio Sci. 4: 819-827.

[24]. Nava-Villalba M, González-Pérez G, Liñan-Fernández M, Marco T (2013) Oxidative Stress in Periodontal Disease and Oral Cancer. In Biochemistry, Genetics and Molecular Biology "Oxidative Stress and Chronic Degenerative Diseases-A Role of Antioxidants”. InTech, JanezaTrdine 9, Rijeka, Croatia.

[25]. Newman MG, Takei HH, Klokkevold PR (2006) Carranza’s Clinical Periodontology. (12th Edn), Saunders Elsevier, US.

[26]. Nomura Y, Tamaki Y, Eto A, Kakuta E, Ogino D, et al., (2012) Screening for periodontal diseases using salivary lactate dehydrogenase, hemoglobin level, and statistical modelling. J Dental Sci. 7(4): 379-383.

[27]. O’Brien PM, Ortwine DF, Pavlovsky AG, Picard JA, Sliskovic DR, et al., (2000) Structure-activity relationships and pharmacokinetic analysis for a series of potent, systemically available biphenyl sulfonamide matrix metalloproteinase inhibitors. J Med Chem. 43(2): 156-166.

[28]. Pardo A, Cabrera S, Maldonado M, Selman M (2016) Role of matrix metalloproteinases in the pathogenesis of idiopathic pulmonary fibrosis. Respir Res. 17: 23.

[29]. Peluso I, Raguzzini A (2016) Salivary and Urinary Total Antioxidant Capacity as Biomarkers of Oxidative Stress in Humans. Path Res Inter. 2016: 1-14.

[30]. Sahitya S, Nugala B, Kumar BB (2010) Matrix Metalloproteinases. J Oro Fac Sci. 2: 75-81.

[31]. Sorsa T, Suomalainen K, Uitto VJ (1990) The role of gingival crevicular fluid and salivary interstitial collagenases in human periodontal diseases. Arch Oral Biol. 35:193S-196S.

[32]. Sorsa T, Tjaderhane L, Salo T (2004) Matrix metalloproteinase's in oral diseases. Oral Dis. 10: 311-18.

[33]. Spinale FG (2007) Myocardial matrix remodeling and the matrix metal- 
loproteinases: Influence on cardiac form and function. Physiol Rev. 87(4): 1285-1342.

[34]. Tjäderhane L, Larjava H, Sorsa T, Uitto VJ, Larmas M, et al., (1998) The activation and function of host matrix metalloproteinase's in dentin matrix breakdown in caries lesions. J Dent Res. 77(8): 1622-1629.

[35]. Van Lint P, Libert, C (2007) Chemokine and cytokine processing by matrix metalloproteinases and its effect on leukocyte migration and inflammation. J Leukoc Biol. 82 (6): 1375-1381.

[36]. Varun BR, Nair BJ, Sivakumar TT, Joseph AP (2012) Matrix Metalloproteinase's and their role in Oral diseases: A Review. Oral \& Maxillofacial Pathol J. 3(1): 186-191.

[37]. Verma RP, Hansch C (2007) Matrix metalloproteinases (MMPs): chemicalbiological functions and (Q)SARs. Bioorg Med Chem. 15(6): 2223-22268.

[38]. Visse R, Nagase H (2003) Matrix metalloproteinases and tissue inhibitors of metalloproteinases: structure, function, and biochemistry. Cir Res. 92(8):
$827-839$.

[39]. Waddington RJ, Moseley R, Embery, G (2000) Reactive oxygen species: a potential role in the pathogenesis of periodontal diseases. Oral Dis. 6(3): 138-151.

[40]. Whittaker M, Floyd CD, Brown P, Gearing AJH (1999) Design and therapeutic application of matrix metalloproteinase inhibitors. Chem Rev. 99(9): 2735-2776.

[41]. WHO (2012) Oral health: Fact sheet No 318.

[42]. Young B, O'Dowd G, Woodford P (2014) Wheater's Functional Histology, (6 ${ }^{\text {th }}$ Edn), Churchill Livingstone. 